\title{
MEMBANGUN STRATEGI MEMENANGKAN PASAR PERSAINGAN PADA TOKO PAKAIAN DI KOTA TEGAL
}

\author{
Makmur Sujarwo' ${ }^{1}$, Setyowati Soebroto ${ }^{2}$ \\ Dosen FE Universitas Pancasakti Tegal \\ ${ }^{1}$ makmursujarwo@gmail.com \\ titie.putri@gmail.com
}

\begin{abstract}
This research is aimed to find out how far the improvement of store operation excellence, the increase of store communication effectiveness (visual merchandising), area trading optimization, focused marketing activity and community involvement have been built in clothing stores in Tegal city so that the retailers can win market competition.

This study used a sample of 100 clothing stores in the city of Tegal as respondents. Respondents' answers to the closed questions about the variables studied in this study were then analyzed by using Multiple Regression Test while the answer to the open question was analyzed qualitatively.

The results of this study indicate that increased communication effectiveness in the shop, focused marketing activities and community involvement significantly influence the strategy to win the clothing store retail market in the city of Tegal. For that it should be clothing store retailers can further improve these three variables to win more competitive market.

Of the five variables above, the community involvement variable has the greatest effect for retailers to win the competition market with a score of 0.251. So a retailer to be more active in social activities by providing compensation to the poor and orphans.
\end{abstract}

Keywords: Market winning strategy, excellence store operations, visual merchandising, area trading optimization, focused marketing activities and community involvement.

\begin{abstract}
Abstraksi. Penelitian ini ditujukan untuk mengetahui seberapa jauh peningkatan operasional toko yang excellence, peningkatan efektivitas komunikasi didalam toko (visual merchandising), optimasi trading area, aktivitas pemasaran yang terfokus dan community involvement telah di bangun pada toko-toko pakaian di kota Tegal sehingga para peritel dapat memenangkan pasar persaingan.

Penelitian ini menggunakan sampel sejumlah 100 toko pakaian di kota Tegal sebagai responden. Jawaban responden terhadap pertanyaan-pertanyaan tertutup mengenai variable yang diteliti dalam penelitian ini selanjutnya dianalisis dengan menggunakan Uji Regresi Berganda sedangkan jawaban atas pertanyaan terbuka dianalisis secara kualitatif.

Hasil penelitian ini menunjukan bahwa peningkatan efektivitas komunikasi didalam toko , aktivitas pemasaran terfokus dan community involvement berpengaruh signifikan terhadap strategi memenangkan pasar peritel toko pakaian di kota Tegal. Untuk itu sudah seharusnya para peritel toko pakaian dapat lebih meningkatkan ketiga variabel tersebut agar lebih memenangkan pasar persaingan.

Dari kelima variabel diatas, variabel community involvement paling besar pengaruhnya agar peritel dapat memenangkan pasar persaingan dengan skor 0,251. Maka seorang peritel agar lebih aktif dalam kegiatan sosial masyarakat dengan memberikan santunan fakir miskin dan anak yatim.
\end{abstract}

Kata Kunci: Strategi memenangkan pasar, operasional toko yang excellence, visual merchandising, optimasi trading area, aktivitas pemasaran terfokus dan community involvement.

\section{PENDAHULUAN}

Pasar ritel di Indonesia terus berkembang. Menurut Asosiasi Perusahaan Ritel Indonesia (Aprindo), pertumbuhan bisnis ritel di Indonesia antara $10 \%-15 \%$ per tahun. Penjualan ritel pada tahun 2006 masih sebesar Rp49 triliun, dan melesat hingga mencapai Rp120 triliun pada tahun 2011. Sedangkan pada tahun 2012, pertumbuhan ritel diperkirakan masih sama, yaitu $10 \%$
15\%, atau mencapai Rp138 triliun. Jumlah pendapatan terbesar merupakan kontribusi dari hipermarket, kemudian disusul oleh minimarket dan supermarket. (http://www. marketing.co.id/brand-switching-analysisdalam-industri-ritel-modern/2013).

Didalam micro-marketing, menurut S.Muharram , terdapat konsep piramida memenangkan pasar yang disebut Local Store Marketing yaitu seni dan ilmu bagaimana retailer menggali informasi, 
membina hubungan dan mengkomunikasikan keberadaan toko serta manfaatnya kepada konsumen yang berada di trading areanya, sehingga tercipta loyalitas masyarakat dalam jangka panjang (Sopiah \& Andi Syihabudhin ; 2008, Manajemen bisnis ritel ; Yogyakarta : Andi).

Pada penelitian terdahulu yang dilakukan oleh Ria Arifianti yang berjudul Pelaksanaan Strategi Bauran Eceran pada Pasar Baru Kota Bandung ( Survei pada pedagang Pakaian jadi Wanita) : Volume 1 No. 2 Agustus 2012 dimana hasil penelitian menunjukkan bahwa Pasar Baru telah melakukan strategi bauran eceran. Tetapi dalam pelaksanaannya masih banyak hambatan-hambatan atau keluhankeluhan yang dirasakan konsumen. Keluhan tersebut seperti barang yang mudah luntur, lokasi kios yang rumit dan adanya perbedaan harga antara pembeli banyak dan tidak.

Banyak jenis usaha yang menawarkan produk dan jasa yang sedang berkembang di Tegal , terutama yang bergerak dibidang fashion. Bahkan saat ini banyak peritel yang selain membuka toko pakaian di toko utamanya, mereka juga telah menambah toko ritelnya di pasar-pasar dan supermall. Yang cukup menarik lagi ada diantara peritel tersebut yang menambah lini produknya dengan membuka toko-toko baru. Hal ini tentu dapat meningkatkan persaingan antar jenis bisnis ritel fashion. Ada juga persaingan antara peritel toko dengan peritel tanpa toko. Toko diskon, ruang pamer katalog, dan toko serba ada bersaing untuk memperoleh konsumen yang sama.

Melihat tingkat persaingan peritel toko pakaian yang sangat besar terutama peritel lokal, peneliti merasa perlu untuk melakukan penelitian agar dapat diketahui sejauh mana para peritel lokal di Tegal telah membangun strategi memenangkan pasar persaingan di bisnis ritel tersebut.

\section{PERUMUSAN MASALAH}

Melihat tingkat persaingan bisnis ritel, maka perlu dilakukan penelitian tentang sejauh mana para peritel di Tegal telah mengimplementasikan strategi memenangkan pasar persaingan. Dengan latar belakang tersebut maka permasalahan-permasalahan yang ada atau dihadapi dapat dirumuskan sebagai berikut apakah faktor peningkatan operasional toko yang excellence, faktor peningkatan efektivitas dari komunikasi ritel di dalam toko (-Visual Merchandising), faktor optimasi trading area, faktor aktivitas pemasaran yang terfokus dan faktor community involvement telah di implementasikan pada toko-toko pakaian di kota Tegal sehingga peritel dapat memenangkan pasar?

\section{TINJAUAN LITERATUR DAN PENGEMBANGAN HIPOTESIS}

\section{Bisnis Ritel}

Pengertian Ritel menurut Ma'ruf (2005:7) adalah kegiatan usaha menjual barang atau jasa kepada perorangan untuk keperluan diri sendiri, keluarga atau rumah tangga. Definisi Retailing adalah serangkaian kegiatan usaha yang memberikan nilai tambah pada produk dan jasa yang dijual kepada pelanggan untuk penggunaan pribadi atau keluarga (Levy, 2009: 48).

\section{Piramida memenangkan pasar local store marketing}

Didalam micro-marketing, menurut S.Muharram , terdapat konsep piramida memenangkan pasar yang disebut Local Store Marketing yaitu seni dan ilmu bagaimana retailer menggali informasi, membina hubungan dan mengkomunikasikan keberadaan toko serta manfaatnya kepada konsumen yang berada di trading areanya, sehingga tercipta loyalitas masyarakat dalam jangka panjang. (Sopiah \& Andi Syihabudhin ; 2008, Manajemen bisnis ritel ; Yogyakarta : Andi). Pada Local Store Marketing (LSM) Store Management menetapkan disiplin yang sangat penting untuk membentuk fondasi dari piramida memenangkan pasar, yaitu Store atmosphere yang exellence yang tepat dan efektif, yang meliputi Pengembangan Karyawan (People Development), Kepuasaan Pelanggan (Customer Satisfaction), Pertumbuhan Penjualan (Sales Growth), Pertumbuhan Keuntungan (Profit Growth), dan Praktek Administrasi yang baik (Good Administration Practice). (SM.Frencise.Com 2005). 


\section{Operasional toko yang excellence}

Dengan operasional toko yang excellence berarti toko mampu memberikan beberapa hal kepada konsumen, diantaranya :

a. Produk berkualitas, arti dari kualitas oleh Philip Kotler (1992 : 55 ), Quality is the totality of features and characteristics of a productor service that bear on its ability to satisfy stated or implied needs. Maksud dari definisi di atas adalah kualitas produk merupakan keseluruhan ciri serta sifat barang dan jasa yang berpengaruh pada kemampuan dalam memenuhi kebutuhan dan keinginan yang dinyatakan maupun yang tersirat.

b. Bauran assortment yang tepat, Bauran produk (Product-Mix atau Product Assortment) Product-Mix yang juga dikenal dengan Product Assortmen adalah total keseluruhan dari daftar produk atau Lini produk sebuah perusahaan yang ditawarkan kepada Konsumen. Struktur Bauran Produk Terbagi menjadi 4 dimensi yaitu : Widht (Kelebaran Bauran Produk), Leght(Kepenjangan Bauran Produk), Depth (Keadalam Bauran Produk), Consistency (Konsistensi Bauran Produk) (http:// smallbusiness.chron.com/productmix-639.html).

c. Service dan value yang memuaskan pelanggan

Menurut Kotler \& Keller (2006 : 136), "total customer satisfaction", adalah "menciptakan pelanggan".' Artinya, bahwa untuk dapat mempertahankan kelangsungan hidupnya, sebuah perusahaan harus memiliki konsumen yang merasa suka dan puas terhadap produk yang tawarkan.

\section{Peningkatan efektivitas dari komunikasi ritel di dalam toko ( Visual Merchandising)}

Visual merchandising adalah seni presentasi yang menempatkan merchandiser di fokus yang bertujuan memiliki ketrampilan khusus dalam mendisplay barang pada toko (Iqbal et al., 2011). Fiore, Yah dan Yoh, 2000 dalam Selvaraj dan Swaminathan, 2011, mengemukakan bahwa visual merchandising berfokus pada berbagai aspek konsumen, yang meliputi indra kesenangan, kesenangan afektif dan kesenangan kognitif. Penempatan visual dalam metode merchandise supermarket, telah terjadi peningkatan penekanan pada jenis tata letak toko. Bangunan toko, perlengkapan, peralatan, penampilan warna, alat komunikasi diam, tampilan jendela dan akhirnya pendapat melalui bangunan di dalam toko yang menampilkan seni ritel untuk frame aplikasi yang lebih tinggi (Iqbal et al., 2011).

\section{Optimasi Trading Area}

Dalam Pemasaran Ritel ; Hendri Ma'ruf : 124 : 2006, faktor-faktor dalam mengevaluasi area perdagangan ritel adalah besarnya populasi dan karakteristiknya, kedekatan dengan sumber pemasok, ketersediaan tenaga kerja,situasi persaingan, pertokoan, pusat belanja

\section{Aktivitas pemasaran yang terfokus}

Komponen produk, harga, tempat, dan promosi atau lebih dikenal dengan $4 \mathrm{P}$ (product, price, place, and promotion) dengan menitikberatkan perhatian yang berbedabeda pada keempat variabel tersebut karena tergantung kepada sipembuat keputusan pemasarannya untuk menyesuaikan dengan lingkungan yang cenderung berubah-ubah yang berusaha untuk memenuhi kebutuhan pelanggan dan mencapai tujuan perusahaan, dimana konsep tersebut berlaku bagi bisnis eceran dengan penekanan pada faktor yang berlainan (McCarthy, 1993). Aktivitas pemasaran yang terfokus artinya semua pesan dan aktivitas dari peritel didalam dan di luar toko mencerminkan satu tema sentral. Antara promosi yang dilakukan toko di media baik cetak atau elektronik harus sejalan dengan produk maupun harga yang ditawarkan di dalam toko dan diluar toko. Sopiah \& Andi Syihabudhin ; 2008, Manajemen bisnis ritel ; Yogyakarta : Andi

\section{Community involvement}

Community involvement adalah hubungan yang dibangun dengan publik (stakeholder, stockholder, media, masyarakat yang berada di sekitar perusahaan, dan lain-lain). 
Menurut US Environmental Protection Agency ( 2016), Community involvement adalah proses terlibat dalam dialog dan kerja sama dengan anggota masyarakat.

Berdasarkan hasil uraian di atas maka hipotesis yang diajukan adalah :

1. H1 : membangun operasional toko yang excellence berpengaruh positif terhadap strategi memenangkan pasar pada toko pakaian di Kota Tegal

2. $\mathrm{H} 2$ : membangun peningkatan efektivitas dari komunikasi ritel di dalam toko ( Visual Merchandising) berpengaruh positif terhadap strategi memenangkan pasar pada toko pakaian di Kota Tegal.

3. H3 : membangun Optimasi Trading Area berpengaruh positif terhadap strategi memenangkan pasar pada toko pakaian di Kota Tegal.
4. H4 : membangun aktivitas pemasaran yang terfokus berpengaruh positif terhadap strategi memenangkan pasar pada toko pakaian di Kota Tegal.

5. H5 : membangun community involvement berpengaruh positif terhadap strategi memenangkan pasar pada toko pakaian di Kota Tegal.

\section{Kerangka Pemikiran Teoris}

Kerangka pemikiran teoritis ini menggambarkan adanya peningkatan operasional toko yang excellence, peningkatan efektivitas dari komunikasi ritel di dalam toko (Visual Merchandising), optimasi trading area, aktivitas pemasaran yang terfokus dan community involvement berpengaruh positif terhadap strategi memenangkan pasar pada toko pakaian di Kota Tegal.

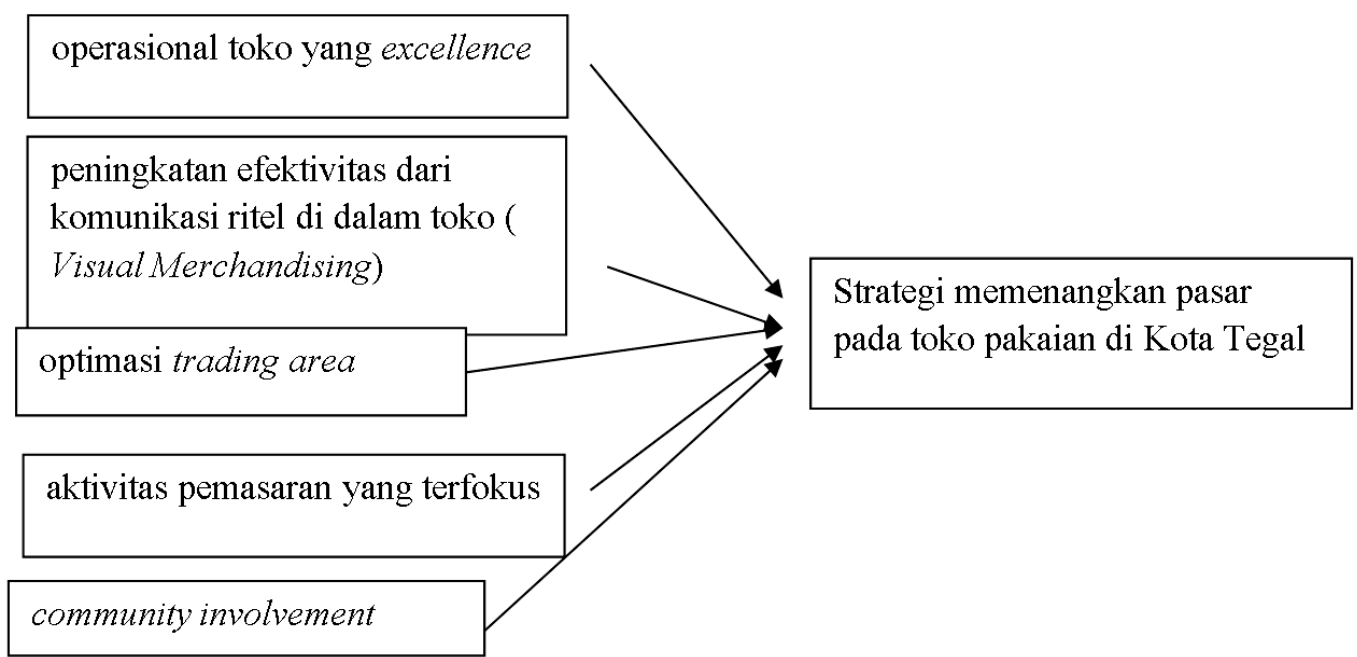

Gambar 1. Kerangka Pemikiran Teoritis

\section{METODE PENELITIAN}

\section{Jenis dan Sumber Data}

Data primer dalam penelitian ini diperoleh secara langsung dari responden yang menjadi peritel toko pakaian di kota Tegal.

\section{Populasi dan Sampel}

Penelitian ini sampel yang diambil dengan menggunakan jenis Non-Probability Sample. Peneliti menggunakan non-probability sampling, karena beberapa alasan. Salah satu metode yang digunakan untuk menentukan jumlah sampel adalah menggunakan rumus Slovin (Sevilla et. al., 1960:182).

$$
n=\frac{N}{1+N e^{2}}
$$

dimana ;

$n$ : jumlah sampel, $\mathrm{N}$ : jumlah populasi, e:

batas toleransi kesalahan (error tolerance)

$$
\frac{\mathrm{n}=150=100 \text { toko pakaian. }}{\left(1+200^{*} 0,05^{\wedge} 2\right)}
$$


Dalam penelitian ini jumlah sampel yang diolah sebanyak 100 responden.

\section{METODE PENGUMPULAN DATA}

Metode pengumpulan data yang digunakan dalam penelitian ini adalah menggunakan kuesioner. Dengan kuesioner ini, responden diharapkan membaca dan menjawab pertanyaan yang diajukan oleh peneliti. Setelah itu, diharapkan langsung adanya tanggapan dari responden dan dapat langsung dikumpulkan oleh peneliti setelah mereka mengisinya. Pertanyaan-pertanyaan dalam kuesioner dibuat dengan menggunakan skala likert 5 poin (1 : Sangat Tidak Setuju hingga 5 : Sangat Setuju).

\section{Teknik Analisis Data}

Teknik analisis yang digunakan dalam penelitian ini adalah menggunakan teknik analisis regresi untuk mengolah dan membahas data yang telah diperoleh dan unutk menguji hipotesis yang diajukan. Dengan teknik regresi kita dapat menyimpulkan secara langsung mengenai pengaruh masing-masing variable bebas yang digunakan secara bersama-sama.

Hair et al (1998) menyatakan bahwa regresi berganda merupakan teknik statistik yang menjelaskan keterkaitan antara variabel terikat dengan beberapa variable bebas. Regresi berganda juga dapat memperkirakan kemampuan prediksi dari serangkaian variabel bebas terhadap variabel terikat ( Hair et all, 1995).

Berikut ini adalah persamaan regresi yang digunakan dalam penelitian ini :

$$
Y=a+b 1 X 1+b 2 X 2+b 3 X 3+\ldots . . b k X i k+e i
$$

Keterangan :

\begin{tabular}{|c|c|}
\hline $\mathbf{Y}$ & $\begin{array}{l}\text { : Strategi memenangkan pasar ; X1 } \\
\text { Operasional toko yang excellence }\end{array}$ \\
\hline $\mathbf{X} 2$ & $\begin{array}{l}\text { Meningkatkan efektivitas dari } \\
\text { komunikasi ritel di dalam toko } \\
\text { Visual Merchandising) }\end{array}$ \\
\hline $\mathbf{X 3}$ & $\begin{array}{l}\text { : Optimasi trading area ; X4 : } \\
\text { Aktivitas Pemasaran yang terfokus }\end{array}$ \\
\hline $\mathbf{X}$ & : Community Involvement \\
\hline & $\begin{array}{l}\text { : Konstanta } \\
\text { : Koefisien Regresi }\end{array}$ \\
\hline
\end{tabular}

\section{Koefisien Determinasi $\left(\mathbf{R}^{2}\right)$}

Menurut Ghozali (2007: 83) bahwa koefisien determinasi pada intinya mengukur seberapa jauh kemampuan model dalam menerangkan variasi variabel dependen. Nilai koefisien determinasi adalah antara nol dan satu. Nilai koefisien determinasi yang kecil berarti kemampuan variabel-variabel independent dalam menjelaskan variasi variabel dependen amat terbatas. Untuk menentukan nilai koefisien determinasi dinyatakan dengan nilai Adjusted $R$ Square. Adapun rumus koefisien determinasi adalah : $\mathrm{R} 2=(\mathrm{r}) 2 \times 100 \%$ dimana $: \mathrm{R} 2=$ koefisien determinasi ; $r=$ koefisien korelasi

\section{PENGUJIAN HIPOTESA}

\section{Uji t (Uji Parsial)}

Uji t yaitu suatu uji untuk mengetahui pengaruh operasional toko yang excellence, visual merchandising, optimasi trading area,aktivitas pemasaran terfokus dan community involvement terhadap strategi memenangkan pasar persaingan peritel toko pakaian secara parsial.

2. Uji F (Uji Simultan)

Uji F yaitu suatu uji untuk mengetahui pengaruh operasional toko yang excellence, visual merchandising, optimasi trading area, aktivitas pemasaran terfokus dan community involvement terhadap strategi memenangkan pasar persaingan peritel toko pakaian secara bersama-sama.

\section{DIMENSIONALISASI VARIABEL}

1. Variabel operasional toko yang excellence, terdiri dari dimensi variabel produk berkualitas (dengan indikatornya produk tidak cacat, produk sempurna dan produk sesuai kebutuhan konsumen), dimensi bauran assortment ( dengan indikatornya bangunan interior dan eksterior toko,penampilan warna dan display khusus) dan service dan value ( dengan indikatornya produk dengan service excellent, harga yang murah)

2. Variabel peningkatan efektivitas dari komunikasi ritel di dalam toko ( Visual Merchandising) terdiri dari dimensi variabel bangunan toko (dengan indikator 
desain iterior dan eksterior) dan dimensi variabel alat komunikasi diam dengan indikator berupa display produk / merek khusus.

3. Variabel optimasi trading area terdiri dari dimensi variabel sumber pemasok ( dengan indikator terdiri dari kecepatan penyediaan merchandise, kualitas produk yang terjaga dan biaya pengiriman), dimensi variabel ketersediaan tenaga kerja (dengan indikator terdiri dari mudah dicari dan berpengalaman) dan variabel situasi persaingan dengan indikatornya persaingan di sekitar toko.

4. Variabel aktivitas pemasaran yang terfokus terdiri dari dimensi variabel produk ( indikatornya produk berkualitas dan sesuai dengan kebutuhan konsumen), dimensi price ( dengan indikatornya harga murah dan terjangkau), dimensi variabel promotion (indikatornya potongan harga, hadiah dan personal selling), dan dimensi variabel place dengan indikatornya layanan delivery order.

5. Variabel community involvement terdiri dari dimensi variabel aktif kegiatan sosial masyarakat dengan indikatornya santunan fakir miskin dan anak yatim.

\section{HASIL PENELITIAN}

Dari survey yang dilakukan, data terkumpul dan diolah dengan menggunakan SPSS 22. Survey yang dilakukan pada peritel toko pakaian di kota Tegal telah menunjukan hasil penelitian tentang : peningkatan operasional toko yang excellence, efektivitas dari komunikasi ritel di dalam toko (Visual Merchandising), optimasi trading area, aktivitas pemasaran yang terfokus dan community involvement telah di bangun pada toko-toko pakaian di kota Tegal sehingga peritel dapat memenangkan pasar.

\section{Uji Validitas}

Berdasarkan hasil uji validitas diketahui bahwa semua indikator adalah valid. Nilai korelasi dari masing-masing indikator dengan probabilitas korelasi [sig. (2-tailed)] sebesar 0,000 hingga 0,049. Sesuai kriteria sebelumnya, maka semua indikator diatas adalah valid, karena nilai probabilitas korelasi [sig. (2-tailed) $<$ dari taraf signifikan
( $\alpha$ ) sebesar 0,05. Dengan demikian masingmasing indikator pada variabel tersebut dapat dilakukan kepada langkah penghitungan selanjutnya.

\section{Uji Reliabilitas}

Dari hasil uji reliabilitas, menunjukan bahwa nilai Cronbach Alpha sebesar 86,4\% yang menurut kriteria Nunnallly (1994) telah melebihi nilai $r$ tabel atau nilai Cronbach Alpha $>0.70$. Maka hasil data memiliki tingkat reliabilitas yang baik, atau dengan kata lain data hasil angket dapat dipercaya.

\section{Uji Multikoleniaritas}

Berdasarkan hasil uji multikolinearitas menunjukkan bahwa nilai dari tolerance dan VIF untuk variabel operasional toko yang excellence, visual merchandising, optimasi trading area, aktivitas pemasaran terfokus dan community involvement menunjukkan nilai yang sama. Dari kriteria pengujian multikolonieritas menunjukkan bahwa semua nilai tolerance lebih besar dari nilai default yang ditentukan sebesar 0,10. Sedangkan untuk nilai VIF juga menunjukkan di bawah angka 10. Sehingga dapat disimpulkan bahwa semua variabel telah memenuhi persyaratan ambang toleransi dan nilai VIF, artinya bahwa variabel bebas terhadap variabel terikat tidak terjadi multikolinieritas.

\section{Uji Normalitas}

Berdasarkan uji statistic grafik distribusi normal, menunjukkan bahwa terbentuk garis lurus diagonal dan data yang menyebar disekitar garis diagonal. Hal ini menunjukkan bahwa data terdistribusi secara normal.

\section{Uji Regresi Linear Berganda}

Dari olahan data menggunakan SPSS, regresi linier berganda antara operasional toko yang excellence, peningkatan efektivitas komunikasi didalam toko (visual merchandising), optimasi trading Area,Aktivitas Pemasaran terfokus dan Community Involvement terhadap Strategi memenangkan pasar (Y) dapat diperoleh persamaan regresi sebagai berikut :

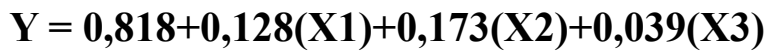

$$
\begin{aligned}
& +0,200(X 4)+0,251(X 5)
\end{aligned}
$$




\section{Koefisien Determinasi}

Besarnya prosentase variabel strategi memenangkan pasar mampu dijelaskan oleh variabel bebas (koefisien determinasi) ditunjukkan dengan nilai Adjusted $R$ Square (R2) yaitu sebesar 0,551 menggunakan R2 karena variabel bebas dalam penelitian ini lebih dari satu, dalam hal ini dapat diartikan bahwa strategi memenangkan pasar mampu dijelaskan oleh operasional toko yang excellence, visual merchandising, optimasi trading area, aktivitas pemasaran terfokus dan community involvement dengan nilai sebesar $55,1 \%$, sedangkan sisanya sebesar $44,9 \%$ dijelaskan oleh variabel lain yang tidak diteliti dalam penelitian ini.

\section{HASIL PENGUJIAN HIPOTESIS}

\section{Hasil Pengujian Hipotesis Secara Parsial dengan Uji-t}

Hasil uji persial (uji t) yang dapat dijelaskan sebagai berikut :

1. Hipotesis 1 menguji pengaruh operasional toko yang excellence terhadap strategi memenangkan pasar menunjukkan hasil bahwa operasional toko yang excellence mempunyai pengaruh positif dan tidak signifikan terhadap strategi memenangkan pasar. Hal ini ditunjukkan oleh koefisien regresi sebesar 0,128 dan tingkat signifikansi sebesar 0,082>0,05.

2. Hipotesis 2 menguji pengaruh peningkatan efektivitas komunikasi didalam toko (visual merchandising) terhadap strategi memenangkan pasar menunjukkan pengaruh positif dan signifikan terhadap strategi memenangkan pasar. Hal ini ditunjukkan oleh koefisien regresi sebesar 0,173 dan tingkat signifikansi sebesar $0,001<0,05$.

3. Hipotesis 3 menguji pengaruh optimasi trading area terhadap strategi memenangkan pasar menunjukkan pengaruh positif dan tidak signifikan terhadap strategi memenangkan pasar. Hal ini ditunjukkan oleh koefisien regresi sebesar 0.039 dan tingkat signifikansi sebesar $0,487>0,05$.

4. Hipotesis 4 menguji pengaruh aktivitas pemasaran terfokus terhadap strategi memenangkan pasar menunjukkan pengaruh positif dan signifikan terhadap strategi memenangkan pasar. Hal ini ditunjukkan oleh koefisien regresi sebesar 0.200 dan tingkat signifikansi sebesar $0,006<0,05$.

5. Hipotesis 5 menguji pengaruh community involvement terhadap strategi memenangkan pasar menunjukkan pengaruh positif dan signifikan terhadap strategi memenangkan pasar. Hal ini ditunjukkan oleh koefisien regresi sebesar 0.251 dan tingkat signifikansi sebesar $0,000<0,05$.

\section{Hasil Uji F (Uji Simultan)}

Dari uji Signifikansi Simultan ( Uji Statistik F) dapat diperoleh bahwa nilai $F$ hitung sebesar 25.264 dengan sig. Sebesar 0.000 . karena probabilitasnya $0.000<0.05$, maka model regresi tersebut dapat dikatakan bahwa operasional toko yang excellence, visual merchandising, optimasi trading area, aktivitas pemasaran terfokus dan community involvement secara bersama-sama berpengaruh terhadap strategi memenangkan pasar. Maka hipotesis yang menyatakan ada pengaruh operasional toko yang excellence, peningkatan efektivitas komunikasi didalam toko (visual merchandising), optimasi trading area, aktivitas pemasaran terfokus dan community involvement secara simultan terhadap strategi memenangkan pasar diterima.

\section{KESIMPULAN}

Penelitian ini menyimpulkan operasional toko yang excellence, peningkatan efektivitas komunikasi didalam toko (visual merchandising), optimasi trading area, aktivitas pemasaran terfokus dan community involvement secara simultan berpengaruh signifikan terhadap strategi memenangkan pasar peritel toko pakaian di kota Tegal.

Untuk pengujian secara parsial hanya tiga variabel yaitu peningkatan efektivitas komunikasi didalam toko (visual merchandising) , aktivitas pemasaran terfokus dan community involvement yang berpengaruh positif dan signifikan terhadap memenangkan pasar peritel toko pakaian di kota Tegal. 


\section{SARAN}

Berdasarkan hasil penelitian bahwa peningkatan efektivitas komunikasi didalam toko (visual merchandising), aktivitas pemasaran terfokus dan community involvement berpengaruh signifikan terhadap strategi memenangkan pasar peritel toko pakaian di kota Tegal sudah seharusnya para peritel toko pakaian agar lebih dapat meningkatkan dan mengimplementasikan ke tiga variabel tersebut agar dapat lebih memenangkan pasar persaingan.

Saran bagi Peritel toko pakaian di Kota Tegal agar dapat memenangkan pasar persaingan dengan beberapa cara yaitu mendesain interior dan eksterior toko lebih bagus, penyediaan alat komunikasi diam berupa display produk/ merek khusus, penyediaan merchandise harus terkontrol dengan baik, produk berkualitas dan bermutu, menyediakan tenaga kerja yang berpengalaman, penetapan harga murah dan terjangkau, memberikan potongan harga dan hadiah, memberikan layanan delivery order dan lebih aktif dalam kegiatan sosial masyarakat dengan memberikan santunan fakir miskin dan anak yatim

Saran untuk penelitian selanjutnya, diharapkan memperluas ruang lingkup penelitian. Jadi bisa menggunakan peritel toko-toko yang lainnya. Hal ini dimaksudkan untuk menghindari subyektifitas peritel toko tertentu.

\section{DAFTAR PUSTAKA}

Arifianti, Ria. 2012, Pelaksanaan Strategi Bauran Eceran pada Pasar Baru Kota Bandung ( Survei pada pedagang Pakaian jadi Wanita) : Volume 1.

Badan Pusat Statistik. 2016.Laporan Bulanan : Edisi 72 : Mei.

Cooper, Donald R.C. dan Emory, William. (1998). Metode Penelitian Bisnis. Erlangga, Jakarta.

Gilbert, David. 2003. Retailing Marketing Management. 2thEdition. England, Endinburgh Gate: Pearson Educated Limited.

Ghozali, I. 2001. Aplikasi Analisis Multivariatedengan SPSS. Badan Penerbit Universitas Diponegoro. Edisi 3. Semarang

Kotler, Philip dan Gary Armstrong ,2001, Prinsip-prinsip Pemasaran, Jilid1, Edisi Kedelapan, Jakarta, Erlangga.

Kotler, P.2002, Manajemen Pemasaran : Jakarta : PT Prenhalindo.

Indriantoro dan Supomo. 1999. Metodologi Penelitian Bisnis untuk Akuntansi dan Manajemen.

Edisi Pertama. BPFE Yogyakarta. Yogyakarta.

Ma'ruf, Hendri. 2005. Pemasaran Ritel. Jakarta : PT Gramedia Pustaka Utama.

Sopiah, Syihabudhin. 2008, Manajemen Bisnis Ritel. Yogyakarta : ANDI.

Simamora, Bilson.2004, Riset Pemasaran, Falsafah, Teori, dan Aplikasi. Jakarta : PT Gramedia Pustaka Utama.

Stanton, William, J.,(2001), Prinsip-prinsip Pemasaran, Jilid Ketujuh, Penerbit Erlangga, Jakarta.

Boston College Center for Corporate Citizenship (2014)

www.S.Muharram.SM.Frencise.Com 2005

www.marketing.co.id/brand-switching-analysis-dalam-industri-ritel-modern/2013.

www.industri.bisnis.com/read/20150918/12/473864/ekonomi-lesu-penjualan-barang-ritel-dijateng-anjlok-30-

www.smallbusiness.chron.com/product-mix-639.html. 


\section{LAMPIRAN-LAMPIRAN}

\section{Hasil Uji Validitas}

Tabel 1

Hasil Uji Validitas

\begin{tabular}{|c|c|c|c|c|}
\hline Variabel & Indikator & $\begin{array}{c}\text { Nilai } \\
\text { Korelasi } \\
\text { (Pearson } \\
\text { Corellation) }\end{array}$ & $\begin{array}{c}\text { Probabilitas } \\
\text { Korelasi [sig. } \\
\text { (2-tailed)] }\end{array}$ & Kesimpulan \\
\hline \multirow{4}{*}{ Operasional toko yang excellence } & $\mathrm{X} 1.1$ & 0.437 & .000 & Valid \\
\hline & $\mathrm{X} 1.2$ & 0.264 & .008 & Valid \\
\hline & $\mathrm{X} 1.3$ & 0.286 & .004 & Valid \\
\hline & $\mathrm{X} 1.4$ & 0.402 & .000 & Valid \\
\hline \multirow{2}{*}{ Visual Merchandising } & $\mathrm{X} 2.1$ & 0.600 & .000 & Valid \\
\hline & $\mathrm{X} 2.2$ & 0.221 & .027 & Valid \\
\hline \multirow{6}{*}{ Optimasi Trading Area } & $\mathrm{X} 3.1$ & 0.286 & .004 & Valid \\
\hline & $\mathrm{X} 3.2$ & 0.445 & .000 & Valid \\
\hline & $\mathrm{X} 3.3$ & 0205 & .041 & Valid \\
\hline & $\mathrm{X} 3.4$ & 0.302 & .002 & Valid \\
\hline & $\mathrm{X} 3.5$ & 0.197 & .049 & Valid \\
\hline & $\mathrm{X} 3.6$ & 0.286 & .004 & Valid \\
\hline \multirow{6}{*}{ Aktivitas Pemasaran terfokus } & $\mathrm{X} 4.1$ & 0.331 & .001 & Valid \\
\hline & $\mathrm{X} 4.2$ & 0.306 & .002 & Valid \\
\hline & $\mathrm{X} 4.3$ & 0.284 & .004 & Valid \\
\hline & $\mathrm{X} 4.4$ & 0.491 & .000 & Valid \\
\hline & $\mathrm{X} 4.5$ & 0.293 & .003 & Valid \\
\hline & $\mathrm{X} 4.6$ & 0.491 & .000 & Valid \\
\hline \multirow[t]{2}{*}{ Community Involvement } & $\mathrm{X} 5$ & 0.605 & .000 & Valid \\
\hline & Y1.1 & 0.437 & .000 & Valid \\
\hline \multirow{4}{*}{ Strategi memenangkan pasar } & Y1.2 & 0.600 & .000 & Valid \\
\hline & Y1.3 & 0.445 & .000 & Valid \\
\hline & Y1.4 & 0.284 & .004 & Valid \\
\hline & Y1.5 & 0.605 & .000 & Valid \\
\hline
\end{tabular}

Sumber: hasil olahan SPSS

\section{Hasil Uji Reliabilitas}

Tabel 2

Hasil Uji Reliabilitas

\begin{tabular}{ccc}
\hline \multicolumn{3}{c}{ Reliability Statistics } \\
\hline Cronbach's Alpha & Cronbach's Alpha Based on Standardized Items & N of Items \\
.861 & .864 & 23 \\
\hline \multicolumn{2}{c}{ Sumber : hasil olahan SPSS }
\end{tabular}




\section{Hasil Uji Multikoleniaritas}

Tabel 3

Hasil Uji Multikoleniaritas

\begin{tabular}{|c|c|c|c|c|c|c|c|c|}
\hline \multicolumn{9}{|c|}{ Coefficients $^{\mathrm{a}}$} \\
\hline & \multirow[t]{2}{*}{ Model } & \multicolumn{2}{|c|}{$\begin{array}{c}\text { Unstandardized } \\
\text { Coefficients }\end{array}$} & \multirow{2}{*}{$\begin{array}{c}\text { Standardized } \\
\text { Coefficients }\end{array}$} & \multirow[t]{2}{*}{$\mathbf{t}$} & \multirow[t]{2}{*}{ Sig. } & \multicolumn{2}{|c|}{$\begin{array}{c}\text { Collinearity } \\
\text { Statistics }\end{array}$} \\
\hline & & B & Std. Error & & & & Tolerance & VIF \\
\hline \multirow{6}{*}{1} & (Constant) & .818 & .339 & & 2.409 & .018 & & \\
\hline & $\mathrm{X} 1$ & .128 & .073 & .137 & 1.757 & .082 & .744 & 1.345 \\
\hline & $\mathrm{X} 2$ & .173 & .051 & .256 & 3.412 & .001 & .809 & 1.237 \\
\hline & $\mathrm{X} 3$ & .039 & .056 & .054 & .698 & .487 & .756 & 1.323 \\
\hline & $\mathrm{X} 4$ & .200 & .071 & .222 & 2.827 & .006 & .738 & 1.355 \\
\hline & X5 & .251 & .039 & .466 & 6.437 & .000 & .865 & 1.156 \\
\hline
\end{tabular}

Sumber : hasil olahan SPSS

\section{Hasil Uji Normalitas}

Gambar 1

Hasil Uji Normalitas

Normal P-P Plot of Regression Standardized Residual

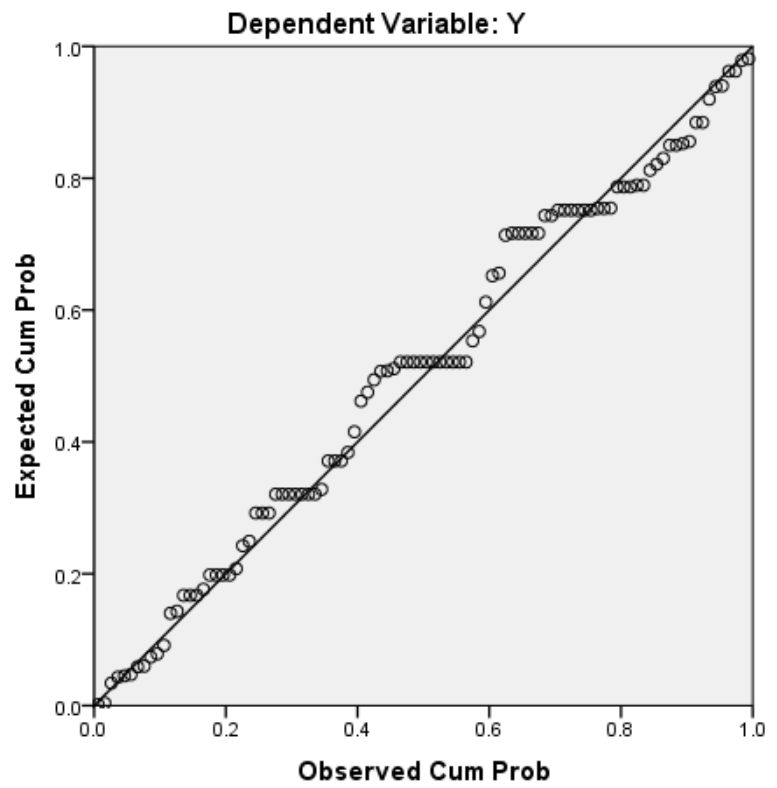

Sumber: hasil olahan SPSS 


\section{Hasil Uji Regresi Linier Berganda}

Tabel 4

Regresi Linear Berganda

\begin{tabular}{|c|c|c|c|c|c|c|}
\hline \multicolumn{7}{|c|}{ Coefficients $^{\mathrm{a}}$} \\
\hline \multirow{2}{*}{\multicolumn{2}{|c|}{ Model }} & \multicolumn{2}{|c|}{ Unstandardized Coefficients } & \multirow{2}{*}{$\frac{\text { Standardized Coefficients }}{\text { Beta }}$} & \multirow{2}{*}{$\mathbf{t}$} & \multirow{2}{*}{ Sig. } \\
\hline & & B & Std. Error & & & \\
\hline \multirow{6}{*}{1} & (Constant) & .818 & .339 & & 2.409 & .018 \\
\hline & $\mathrm{X} 1$ & .128 & .073 & .137 & 1.757 & .082 \\
\hline & $\mathrm{X} 2$ & .173 & .051 & .256 & 3.412 & .001 \\
\hline & $\mathrm{X} 3$ & .039 & .056 & .054 & .698 & .487 \\
\hline & $\mathrm{X} 4$ & .200 & .071 & .222 & 2.827 & .006 \\
\hline & $\mathrm{X} 5$ & .251 & .039 & .466 & 6.437 & .000 \\
\hline
\end{tabular}

Sumber : hasil olahan SPSS

\section{Hasil Uji Parsial}

Tabel 6

Hasil Uji Parsial

\begin{tabular}{|c|c|c|c|c|c|c|}
\hline \multicolumn{7}{|c|}{ Coefficients $^{\mathbf{a}}$} \\
\hline \multirow{2}{*}{\multicolumn{2}{|c|}{ Model }} & \multicolumn{2}{|c|}{ Unstandardized Coefficients } & \multirow{2}{*}{$\begin{array}{c}\text { Standardized Coefficients } \\
\text { Beta } \\
\end{array}$} & \multirow{2}{*}{$\mathbf{t}$} & \multirow{2}{*}{ Sig. } \\
\hline & & B & Std. Error & & & \\
\hline \multirow{6}{*}{1} & (Constant) & .818 & .339 & & 2.409 & .018 \\
\hline & $\mathrm{X} 1$ & .128 & .073 & .137 & 1.757 & .082 \\
\hline & $\mathrm{X} 2$ & .173 & .051 & .256 & 3.412 & .001 \\
\hline & $\mathrm{X} 3$ & .039 & .056 & .054 & .698 & .487 \\
\hline & $\mathrm{X} 4$ & .200 & .071 & .222 & 2.827 & .006 \\
\hline & $\mathrm{X} 5$ & .251 & .039 & .466 & 6.437 & .000 \\
\hline \multicolumn{7}{|c|}{ a. Dependent Variable: Y } \\
\hline
\end{tabular}

\section{Hasil Uji Simultan}

Tabel 7

Hasil Uji Simultan

\begin{tabular}{ccccccc}
\hline \multicolumn{7}{c}{ ANOVA $^{\text {a }}$} \\
\hline & Model & Sum of Squares & df & Mean Square & F & Sig. \\
\hline \multirow{2}{*}{1} & Regression & 14.082 & 5 & 2.816 & 25.264 & $.000^{\text {b }}$ \\
& Residual & 10.478 & 94 & .111 & & \\
& Total & 24.560 & 99 & & & \\
\hline
\end{tabular}

a. Dependent Variable: Y

b. Predictors: (Constant), X5, X2, X4, X3, X1

Sumber : hasil olahan SPSS 